\title{
SISTEMA COLABORATIVO NO ENSINO SUPERIOR PÚBLICO
}

\author{
Daniel Suiter ${ }^{1}$ \\ Universidade do Estado de Santa Catarina \\ daniel.suiter@udesc.br \\ Andressa Sasaki Vasques Pacheco \\ Universidade Federal de Santa Catarina \\ andressa.pacheco@ufsc.br
}

\begin{abstract}
Resumo
Este artigo faz uma proposta de um sistema colaborativo no ensino superior público brasileiro como um modelo ou ferramenta estratégica para alcançar seus objetivos e atender de forma mais efetiva as demandas sociais e mercadológicas. Trata-se de pesquisa de natureza básica, quanto aos fins exploratória, quanto aos meios bibliográfica e documental, justificada pela quantidade de vagas novas ofertadas no Brasil versus vagas ocupadas e interessados. Correlaciona a oferta de vagas no curso de Medicina com a questão da saúde pública brasileira como indicador de uma das demandas sociais e da interferência do estado sobre as IES. Conclui-se que o modelo proposto pode ser implementado do nível estratégico até o operacional, com possibilidade de significativo ganho de eficiência e abrangência.
\end{abstract}

Palavras-chave: Ensino superior colaborativo. Colaboração no ensino superior. Ensino superior.

\section{COLLABORATIVE SYSTEM ON THE PUBLIC HIGHER EDUCATION}

\begin{abstract}
This article proposes a collaborative system in Brazilian public higher education as a model or strategic tool to reach its objectives and to meet more effectively the social and market demands. It is a research of a basic nature, as far as the exploratory ends, as to the means such as bibliographical and documentary, justified by the number of new vacancies offered in Brazil versus occupied and interested vacancies, correlated to the medical course contacting with the public health question Brazil as an indicator of one of the social demands and state interference on HEIs, in which it can be concluded that the proposed model can be implemented from the strategic to the operational level, with the possibility of a significant gain in efficiency and comprehensiveness.
\end{abstract}

Keywords: Collaborative higher education, Collaboration in higher education, Higher education.

\footnotetext{
${ }^{1}$ Mestrando em Administração Universitária na Universidade Federal de Santa Catarina - UFSC. Servidor Público na Universidade do Estado de Santa Catarina - Udesc.

2 Doutora em Engenharia e Gestão do Conhecimento pela Universidade Federal de Santa Catarina. Professora Adjunta III da Universidade Federal de Santa Catarina. e-mail: andressa.pacheco@ufsc.br.
} 


\title{
1 INTRODUÇÃO
}

A sociedade atual apresenta como principal característica rápidas mudanças, tanto do ponto de vista de empregabilidade quanto de novas tecnologias, inclusões e exclusões de culturas até novos meios de comunicação. Em paralelo, as demandas sociais e mercadológicas também se alteram, necessitando assim que as instituições de ensino superior públicas (IES) se adéquem em igual velocidade. Para tanto, essas instituições necessitam de flexibilidade e agilidade, e para chegar neste objetivo exige-se um conjunto de ações com elevado grau da complexidade das variáveis envolvidas, tanto do ponto de vista interno às IES como também externo.

Internamente, há diversas dificuldades a serem enfrentadas, como custos de operacionalização e falta de verbas governamentais, entre outras. Externamente, além da concorrência com outras IES públicas e privadas (estas últimas, em alguns casos, deixando a desejar em termos de qualidade), tem-se a mão do Estado interferindo sobre a gestão universitária ao mesmo tempo em que se tem a cobrança da sociedade, pedindo retorno do seu investimento.

Pensando num formato que possa aumentar a abrangência de atuação das IES públicas, fortalecê-las e uni-las, manter ou mesmo reduzir seus custos operacionais e atender de forma mais estratégica aos anseios da sociedade, este trabalho busca responder a seguinte pergunta: a economia colaborativa no sistema de ensino superior público pode ser uma ferramenta ou modelo para melhorar e eficiência do setor?

\section{ECONOMIA COLABORATIVA E GESTÃO DA INFORMAÇÃO}

A economia colaborativa é algo recente no mercado mundial e vem crescendo de forma exponencial, dados os significativos resultados apresentados junto às instituições que estão aderindo a este modelo.

\begin{abstract}
A economia colaborativa representa uma nova maneira de pensar sobre negócios, troca, valor e comunidade. Embora suas definições sejam variadas e os parâmetros continuem a evoluir, atividades e modelos dentro da economia colaborativa permitem o acesso em vez da propriedade, incentivam redes descentralizadas em instituições centralizadas e liberam riqueza (com e sem dinheiro). Eles fazem uso de ativos ociosos e criam novos mercados. Ao fazer isso, muitos também desafiam as formas tradicionais de fazer negócios, regras e regulamentos. (STOKES et al, 2014, p. 7)
\end{abstract}

Conforme Lisboa (2017), há quatro tipo de comunidades colaborativas: coworking, na qual compartilha-se o espaço de trabalho; crowdsourcing, que mobiliza uma multidão, em 
geral on line, para obtenção de serviços ou resolução de problemas; cocriação, o envolvimento de clientes e concorrentes em um processo de produção, e crowdfunding, financiamento coletivo sem a mediação do sistema financeiro, uma espécie de versão renovada do consórcio brasileiro.

Menezes (2015) cita também outro estilo colaborativo: o crowdlearning, que proporciona aprendizado colaborativo. Nele, as pessoas compartilham conhecimentos com quem tem interesse de aprender, demonstrando assim que as pessoas estão se direcionando para atividades coletivas, abrindo mão da propriedade privada, do individualismo, ou do reconhecimento para trabalhar em conjunto, compartilhando experiências, resultados, tempos, dentre outros.

Em 2016 a mesma autora disse que a aprendizagem colaborativa pode ser traduzida em cursos abertos, compartilhamento de habilidades e conhecimento crowdsourced: o primeiro é a modalidade na qual o conteúdo educacional é gratuito e aberto a qualquer pessoa interessada; no segundo, as pessoas se oferecem para ensinar ou compartilhar habilidades; e o terceiro é aquele em que pessoas agregam seus conhecimentos publicamente em uma plataforma, como o Wikipédia.

No modelo de economia colaborativa há um leque significativo de variáveis e dados envolvidos, que necessitam de modelos e ferramentas de gestão:

\footnotetext{
É evidente, na atualidade, que nada poderia funcionar sem uma quantidade significativa de informação como elemento que impulsiona os fenômenos sociais e que é por eles impulsionada. Pessoas e organizações - públicas ou privadas dependem da informação em seus processos decisórios. Entretanto, para ser utilizada estrategicamente, é fundamental que a informação seja gerida em favor da sobrevivência e competitividade organizacional. Este processo, a gestão da informação (GI), é responsável por gerir tanto os recursos internos quanto os externos à organização. (SILVA; TOMAEL, p. 148)
}

A tecnologia da informação (TI) tem papel fundamental junto a gestão do conhecimento (GC) e em alguns casos estas são vistas como sinônimos, porém cada uma tem suas características:

O papel principal da TI é dar suporte à GC, ampliando o alcance e acelerando a
velocidade de transferência do conhecimento. É identificar, desenvolver e implantar
tecnologias que apóiem a comunicação empresarial, o compartilhamento e a gestão
dos ativos de conhecimento. A TI desempenha papel de infra-estrutura, a GC
envolve aspectos humanos e gerenciais. (ROSSETTI; MORALES, p. 124)

Para que ocorra uma adequada gestão de informações, é necessária uma eficiente rede de tecnologia da informação, comum também a economia colaborativa, conforme será demonstrado neste artigo. 


\section{MÉTODO}

Trata-se de pesquisa de natureza básica, quanto aos fins como exploratória, quanto aos meios como bibliográfica e documental.

Foi analisado o Censo Superior Brasileiro do ano de 2016 para avaliar as ofertas de vagas, interessados, ingressantes e taxa de ocupação para justificar que há divergências neste indicador e que este representa uma demanda social e mercadológica.

O ato normativo que dispõe sobre o censo de educação superior é portaria n. 794, de 23 de agosto de 2013, do Ministério da Educação (MEC), que trata de prazos, fornecimento de informações pelas IES, resultados das coletas de dados, diretrizes operacionais, entre outros.

Conforme disposto no site do Instituto Nacional de Estudos e Pesquisas Educacionais (INEP):

O Censo da Educação Superior, realizado anualmente pelo Inep, é o instrumento de pesquisa mais completo do Brasil sobre as instituições de educação superior (IES) que ofertam cursos de graduação e sequencias de formação específica, além de seus alunos e docentes. Essa coleta tem como objetivo de oferecer à comunidade acadêmica e à sociedade em geral informações detalhadas sobre a situação e as grandes tendências do setor.

O Censo da Educação Superior reúne informações sobre as instituições de ensino superior, seus cursos de graduação presencial ou a distância, cursos sequenciais, vagas oferecidas, inscrições, matrículas, ingressantes e concluintes e informações sobre docentes nas diferentes formas de organização acadêmica e categoria administrativa.

Os dados são coletados a partir do preenchimento dos questionários, por parte das Instituições de Ensino Superior (IES) e por importação de dados do Sistema e-MEC. Durante o período de preenchimento do questionário, os pesquisadores institucionais (PIs) podem fazer, a qualquer momento, alterações ou inclusões necessárias nos dados das respectivas instituições. Após esse período, o Inep verifica a consistência das informações coletadas. O sistema do Censo é então reaberto para conferência e validação dos dados pelas IES.

Passado esse período de validação ou correção das informações prestadas pelas IES, o Inep realiza rotinas de análise na base de dados do Censo para conferir as informações. Após essa fase de conferência, em colaboração com os pesquisadores institucionais, o Censo é finalizado. Os dados são divulgados e a Sinopse Estatísticas é publicada. Depois disso não pode mais haver alteração nas informações, pois passam a ser estatísticas oficiais. (INEP, 2015)

As estatísticas produzidas oferecem informações sobre ingressos, matrículas, concluintes, recursos de acessibilidade, entre outros, além de subsidiar o planejamento de políticas públicas, e contribui para o cálculo de indicadores de qualidade como o Conceito Preliminar de Curso (CPC) e o Índice Geral de Cursos (IGC). As informações são divulgadas pelo INEP em forma de sinopse estatística, de forma transparente e acessível à população. 


\section{ARTIGO}

INOVAÇÃO

\section{ANÁLISE DOS DADOS}

Para justificar a necessidade de um novo modelo de gestão universitária, cabe aqui a identificação e análise de um indicador que permita avaliar as demandas sociais e mercadológicas, e, para tal, será utilizada a relação entre oferta de vagas e a procura por segmento institucional.

Primeiramente, vamos analisar a oferta de vagas no Ensino Superior Brasileiro, separando-as por Categorias Administrativas, das quais analisaremos o percentual de ocupação das vagas ofertadas.

Tabela 01 - Novas vagas ofertadas x ingressantes no Brasil no ano de 2016.

\begin{tabular}{|c|c|c|c|c|c|}
\hline \multicolumn{6}{|c|}{ CENSO SUPERIOR 2016 - Total Geral } \\
\hline \multirow{2}{*}{\multicolumn{3}{|c|}{$\begin{array}{c}\text { Unidade da Federação / Categoria } \\
\text { Administrativa }\end{array}$}} & \multicolumn{2}{|c|}{ Total Geral } & \multirow{3}{*}{$\begin{array}{c}\text { Percentual Ingressos } \\
\text { /Vagas oferecidas } \\
47 \%\end{array}$} \\
\hline & & & \multirow{2}{*}{$\begin{array}{l}\text { Novas Vagas } \\
\text { Oferecidas } \\
3.937 .129\end{array}$} & \multirow{2}{*}{$\begin{array}{c}\text { Novos } \\
\text { Ingressos } \\
1.858 .106\end{array}$} & \\
\hline Brasil & \multirow{5}{*}{ Pública } & & & & \\
\hline & & & 529.239 & 457.288 & $86 \%$ \\
\hline & & Federal & 315.722 & 291.749 & $92 \%$ \\
\hline & & Estadual & 155.450 & 135.549 & $87 \%$ \\
\hline & & Municipal & 58.067 & 29.990 & $52 \%$ \\
\hline & Privada & & 3.407 .890 & 1.400 .818 & $41 \%$ \\
\hline
\end{tabular}

Fonte: Instituto Nacional de Estudos e Pesquisas Educacionais Anísio Teixeira (2017).

O Inep considera como novas vagas oferecidas e novos ingressos o quantitativo vinculado a um dos seguintes processos seletivos: vestibular, Enem (Exame Nacional do Ensino Médio), avaliação seriada (uma prova ao final de cada ano do ensino médio) e seleção simplificada (entrevista, avaliação de currículos e outros).

Observa-se que as instituições públicas apresentam taxa de ocupação razoável, mas não ideal; porém, dentro desse contexto há cursos com baixíssimas demandas de alunos. Por algum determinado motivo algumas IES ainda oferecem estas vagas, onerando o Estado, subaproveitando recursos físicos e humanos e impactando negativamente na imagem da gestão do ensino superior público brasileiro, visto que conforme tabela acima há mais vagas sendo ofertadas do que novos ingressantes.

Em contrapartida, há uma forte demanda de interessados pelo curso de medicina. Esse curso foi selecionado por este pesquisador para este estudo por representar não somente uma demanda de mercado, mas também por representar uma demanda social ligada a saúde pública e particular nacional. 
Tabela 02: Novas vagas ofertadas x candidatos inscritos no processo seletivo - Curso de Medicina.

\begin{tabular}{|c|c|c|}
\hline \multicolumn{3}{|c|}{ CENSO SUPERIOR 2016 - Brasil } \\
\hline Curso & N. de Vagas Oferecidas & N. de Candidatos Inscritos \\
\hline Medicina & 27.857 & 1.059 .652 \\
\hline
\end{tabular}

Fonte: Instituto Nacional de Estudos e Pesquisas Educacionais Anísio Teixeira (2017).

Ao comparar as duas tabelas, percebe-se que, das 3.937.129 de todas as vagas oferecidas no Brasil, apenas $0,71 \%$ das vagas são para medicina, porém os 1.059.652 interessados e inscritos no respectivo processo seletivo representam $7,77 \%$ do total de inscritos do Brasil, comprovando assim a discrepância entre desejos da sociedade e a oferta de vagas universitárias.

Sabe-se que o curso de medicina é um curso caro e que deve seguir rigorosas legislações para sua implementação, sendo esse um dos fatores que dificultam a abertura de novas vagas. Essa falta de vagas é motivo para questionamento da população que sofre com o atendimento em saúde, principalmente na saúde pública, e consequentemente culpa as IES por isso; porém, nesse caso, além destas dificuldades há também o Estado interferindo na autonomia universitária, prejudicando assim sua gestão.

Pode-se exemplificar a intervenção do Estado nas IES com a portaria do Ministério da Educação n. 328, de 5 abril de 2018, que impediu que novos cursos ou vagas do curso de medicina fossem ofertados durante 5 anos:

\footnotetext{
Art. $1^{\circ}$ Fica suspensa por cinco anos a publicação de editais de chamamento público para autorização de novos cursos de graduação em Medicina, nos termos do art. $3^{\circ}$ da Lei $\mathrm{n}^{\circ} 12.871$, de 22 de outubro de 2013, e o protocolo de pedidos de aumento de vagas em cursos de graduação em Medicina ofertados por instituições de educação superior vinculadas ao sistema federal de ensino, de que trata o art. 40 do Decreto $\mathrm{n}^{\circ}$ 9.235, de 15 de dezembro de 2017 (BRASIL, 2018).
}

A oferta de vagas para estudantes de medicina é uma questão de demanda de mercado. O Estado deveria incentivar a formação de profissionais médicos, que barateariam seus preços em virtude da concorrência e consequentemente atenderiam maior número de habitantes a um menor custo; ou seja, apesar da atual realidade deplorável em termos de saúde pública brasileira, uma IES não poderá abrir novas vagas por conta dessa moratória de 5 anos mesmo que apresente números impressionantes de interessados, conforme apresentado na tabela 2, que demonstra uma média de 38 candidatos interessados por vaga ofertada em todo Brasil para o referido curso.

Nesse caso, da suspensão por 5 anos de criação de novas vagas nos cursos de medicina, a justificativa apresentada para sua formulação é a baixa qualidade dos 
profissionais formados. Porém, entende-se que sejam punidas as IES que estão formando estes maus profissionais e não todo o Sistema de Ensino Superior; ou seja, o Estado poderia utilizar outros meios para filtrar tais acadêmicos e instituições, através de ferramentas como o Exame Nacional de Desempenho dos Estudantes (Enade) ou fazendo provas semelhantes a da Ordem dos Advogados do Brasil.

\section{PROPOSTA DE MODELO}

A proposta deste modelo é atender não somente a oferta de vaga estrategicamente entre as IES públicas, mas também melhorar a eficiência de todo o conjunto universitário que o envolve de acordo com a necessidade identificada.

\subsection{REFORÇAR A ATUAÇÃO DO ENSINO SUPERIOR PÚBLICO}

Dentro deste sistema de ensino superior encontram-se as instituições de ensino privadas, que apresentam características positivas, como a injeção de novas tecnológicas no meio acadêmico, alcance de novas regiões ainda não abraçadas pelo setor público, rápida adaptação estrutural, mas também apresentam características que geram questionamento à respeito de mercantilização do ensino superior. De acordo com Bianchetti e Sguissardi (2012), trata-se da comercialização de serviços sem demais preocupações com a qualidade do ensino, na qual há doze grandes multinacionais da área de ensino superior abocanhando assim significativa fatia dos alunos matriculados no Brasil.

Se considerarmos este contexto, onde há divergências entre oferta e procura, e entendermos que algumas instituições privadas estão focadas na comercialização de seus produtos, cabe às instituições públicas se readequar e atuar de forma estratégica e colaborativa, agindo de forma proativa dentro de uma eficiente rede de informações que permita ações de curto, médio e longo prazo.

Visualizado esse cenário, onde ofertas e demandas estão em desacordo com as necessidades da sociedade, cabe um olhar estratégico e uma reflexão quanto às ações colaborativas entre as IES públicas, visto que algumas instituições fazem concorrência entre cursos em regiões com pouca demanda.

\subsection{APROVEITAMENTO DE ESTRUTURAS INSTITUCIONAIS E FLEXIBILIZAÇÃO CURRICULAR}


Analisando agora a questão operacional, o ideal seria que servidores pudessem atender outras IES, dado o nível de especialização e o aproveitamento destes professores ou técnicos em outros cursos ou disciplinas afins e considerando a exigência do mercado quanto a necessidade de aprofundado conhecimento no assunto:

A colaboração é algo de grande importância no atual contexto tecnológico em que estamos vivendo, e com a competitividade em que se encontra o mercado. Nas organizações as pessoas devem saber trabalhar em conjunto, interagindo para que sejam criados novos conhecimentos e habilidades (CONTI, PINTO; 2010, p. 9).

Entende-se que essa possa ser uma das soluções para o atual problema de baixa disponibilidade das IES públicas em reformular currículos ou substituir cursos defasados por novas demandas de mercado mantendo a qualidade dos professores. Entende-se que docentes mais especializados tendem a dar aulas com melhor aprofundamento e conhecimento na área, ao contrário da pratica utilizada por algumas IES privadas, que buscam professores generalistas para atuarem em diversas áreas e normalmente a um custo significativamente menor; ou seja, haveria disponibilidade de um maior número de professores especialistas para atender um maior número de cursos.

A estrutura física, atualmente subutilizada, seria prevista dentro de uma lógica de coworking entre as instituições; ou seja, semelhante ao que ocorre em outros segmentos, na qual empresas e pessoas físicas compartilham seus bens - como, por exemplo, equipamentos, que antes eram comprados para serem usados em poucos minutos em sua vida útil, agora ficam à disposição de outros usuários; ou os veículos pessoais, que hoje são disponibilizados para caronas cujos custos são divididos pelos usuários.

\subsection{DESAFIOS}

Os benefícios para as IES e para a sociedade são significativos, com a implementação total ou parcial destas comunidades colaborativas, tanto do ponto de vista de custos, até a abrangência e impacto das ações. Contudo, para a implementação deste modelo é necessário que uma barreira seja superada: a quebra de paradigma. Os gestores terão que ver outras IES não como concorrentes, mas sim como parceiras, e interagirem de forma transparente em um processo de ganhos comuns, melhorando o retorno esperado à população:

De modo legítimo, a população em geral, premida pelas necessidades da sobrevivência ou identificadas com projetos culturais emancipatórios, reclama a necessária contribuição das universidades públicas, cobrança de retorno mais que justo dos resultados do trabalho desenvolvido nas universidades com financiamento da própria sociedade (SEVERINO, 2008, p. 85). 
Outro desafio é a estruturação de uma adequada rede de tecnologia de informações e sua gestão dentro da realidade universitária: a coutilização de laboratórios, servidores, equipamentos e espaços físicos demonstra a necessidade de uma plataforma ágil e descentralizada.

\footnotetext{
À medida que os ambientes profissionais e de negócios se tornam mais complexos e mutantes, a informação se transforma, indiscutivelmente, em uma arma capaz de garantir a devida antecipação e análise de tendências, bem como a capacidade de adaptação, de aprendizagem e de inovação (BARBOSA, 2008, p. 2).
}

Além dos itens citados, a gestão de informações deve considerar as normativas próprias do meio universitário, como leis federais, estaduais e municipais, além das próprias normativas internas de cada IES e seus interesses. É preciso também considerar diferentes óticas, como setor de licitação, leis trabalhistas, considerações didático pedagógicas, atendimento social, pesquisa, extensão, entre outros; ou seja, um cenário desafiador que exigirá profissionais extremamente qualificados e motivados a alcançar o objetivo comum, que é atender de forma mais eficiente e justa a sociedade brasileira.

Certamente o maior desafio é a adequação de legislações por parte do Estado, que permitam a implantação e operacionalização deste modelo no setor universitário, pois novas demandam surgirão. Por exemplo, há que se pensar em um novo modelo de avaliação institucional a ser utilizado pelo Ministério da Educação, pois atualmente se considera estrutura física, acessibilidade, pesquisas e outros critérios separados por IES, ou seja, não está previsto dentro deste modelo colaborativo.

\section{CONCLUSÃO}

Percebe-se que as demandas sociais e mercadológicas estão em desacordo com as ofertas de alguns cursos de graduação no Brasil e conclui-se que há possibilidade de significativo ganho de eficiência das instituições de ensino superior públicas. O modelo de gestão colaborativa contribuirá para esse ganho, pois ações estrategicamente distribuídas entre os envolvidos, como lançamentos de cursos e aberturas de vagas coordenadas, com possibilidade de compartilhamento de espaços físicos, equipamentos, tecnologias e servidores, facilitarão a inclusão de novos cidadãos ao ensino superior, pautados numa manutenção ou talvez redução de custos operacionais.

Os principais desafios para a implementação do modelo estão relacionados às políticas públicas, que poderiam permitir maior flexibilidade e novos meios de operacionalização, nas 
8 INOVAÇÃo

quais o Estado tivesse um papel mais adaptativo, integrativo e menos intervencionista junto as IES, pois muitas vezes o aparato burocrático impede ações de ordem complexas, como é o caso. Também se faz necessária a quebra de paradigmas entre as IES públicas, mantendo este formato colaborativo e estratégico em contrário a visão institucional individualista; por último, é preciso implantar uma adequada rede de tecnologia e gestão da informação, dada a quantidade de dados envolvidos.

Tal formato, se implementado, tornará as IES públicas mais flexíveis e adaptativas às demandas sociais e mercadológicas, porém mantendo ou melhorando a qualidade do ensino, e consequentemente fortalecendo o sistema de ensino superior público brasileiro. 


\section{REFERÊNCIAS}

BARBOSA, Ricardo Rodrigues. Gestão da informação e do conhecimento: origens, polêmicas e perspectivas. Informação \& Informação, Londrina, v. 13, n. 1 esp, p. 1-25, 2008. Disponível em: http://www.uel.br/revistas/uel/index.php/informacao/article/view/1843. Acesso em: 15 out. 2018.

BIANCHETTI, Lucídio; SGUISSARDI Valdemar. Da Universidade a Commoditycidade: ou de como e quando, se a educação/formação é sacrificada no altar do mercado, o futuro da universidade se situaria em algum lugar do passado. Campinas, SP: Mercado de Letras, 2017.

BRASIL, Ministério da Educação. Portaria n. 325 de 5 abril 2018. Dispõe sobre a suspensão do protocolo de pedidos de aumento de vagas e de novos editais de chamamento público para autorização de cursos de graduação em Medicina e institui o Grupo de Trabalho para análise e proposição acerca da reorientação da formação médica. Brasília, DF, abr. 2018. Disponível em: https://abmes.org.br/arquivos/legislacoes/Port-MEC-328-2018-0405.pdf. Acesso em: 11 set. 2018.

BRASIL, Ministério da Educação. Portaria n. 794 de 23 de agosto de 2013. Dispõe sobre o censo de educação superior. Brasília, DF, ago. 2018. Disponível em: http://download.inep.g ov.br/educacao_superior/censo_superior/legislacao/2014/portaria_n_794_26_agosto_2013_ce nso.pdf. Acesso em 27 nov. 2018.

CONTI, Daiana Lindaura; PINTO, Maria Carolina Carlos. Ferramentas colaborativas para bibliotecas. Revista ACB, Florianópolis, v. 15, n. 1, p. 7-21, jan./jun. 2010. Disponível em: https://revistaacb.emnuvens.com.br/racb/issue/view/45. Acesso em: 27 nov. 2018.

MENEZES, Uiara Gonçalves de. Consumo colaborativo: relação entre confiança e cooperação. Revista Metropolitana de Sustentabilidade, São Paulo, v. 5, n. 2, p. 195-111, 2015. Disponível em: http://revistaseletronicas.fmu.br/index.php/rms/ article/view/632. Acesso em: 29 out. 2018.

MENEZES, Uiara Gonçalves de. Desenvolvimento sustentável e economia colaborativa: um estudo de múltiplos casos no Brasil. 2016. Tese (Doutorado em Administração) Universidade Federal do Rio Grande do Sul, Escola de Administração, Porto Alegre, 2016. Disponível em: https://www.lume.ufrgs.br/handle/10183/143942. Acesso em: 29 out. 2018.

INSTITUTO NACIONAL DE ESTUDOS E PESQUISAS EDUCACIONAIS ANÍSIO TEIXEIRA. Sinopse Estatística da Educação Superior 2016. Brasília: Inep, 2017. Disponível em: http://portal.inep.gov.br/basica-censo-escolar-sinopse-sinopse. Acesso em: 11 set. 2018.

INSTITUTO NACIONAL DE ESTUDOS E PESQUISAS EDUCACIONAIS ANÍSIO TEIXEIRA. Site Institucional. Brasília: Inep, 2015. Disponível em: http://portal.inep.gov.br/web/guest/censo-da-educacao-superior/. Acesso em: 27 nov. 2018.

LISBOA, Armando de Melo. Economia compartilhada/Economia solidária: Interfaces, continuidades e descontinuidades. Revista NECAT-Revista do Núcleo de Estudos de Economia Catarinense, Florianópolis, v. 6, n. 11, p. 8-32, 2017. Disponível em: http://stat.intraducoes.incubadora.ufsc.br/index.php/necat/article/view/4854. Acesso em: 15 out. 2018. 
ROSSETTI, Adroaldo Guimarães; MORALES, Aran Bey Tcholakian. O papel da tecnologia da informação na gestão do conhecimento. Ciência da Informação, Brasília, DF, v. 36, n. 1, p. 124-135, 2007. Disponível em: http://www.scielo.br/pdf/ci/v36n1/a09v36n1. Acesso em: 26 nov. 2018.

SEVERINO, Antônio Joaquim. O ensino superior brasileiro: novas configurações e velhos desafios. Educar em revista, Curitiba, n. 31, p. 73-89, 2008. Disponível em: http://www.scielo.br/pdf/er/n31/n31a06. Acesso em 14 set. 2018.

SILVA, Terezinha Elisabeth da; TOMAÉL, Maria Inês. A gestão da informação nas organizações. Informação \& Informação, Londrina, v. 12, n. 2, p. 148-149, 2007. Disponível em: http://www.uel.br/revistas/uel/index.php/informacao/article/view/1806. Acesso em: 26 nov. 2018.

STOKES, Kathleen et al. Making sense of the UK collaborative economy. London: Nesta, 2014. Disponível em: https://collaboriamo.org/media/2014/10/making_sense_of_the_uk_colla borative_economy_14.pdf. Acesso em: 29 out. 2018. 